\section{Use of Hydroxychloroquine in Japan}

\section{To the Editor:}

Antimalarial agents have been used for the treatment of inflammatory diseases for the last half century, with hydroxychloroquine (HCQ) being approved in the United States in $1955^{1}$. In addition to its common use in systemic lupus erythematosus (SLE), including cutaneous forms, it has also proven useful in treating rheumatoid arthritis (RA) ${ }^{2,3,4}$ and Sjögren's syndrome $^{5}$. In SLE, antimalarial agents have been shown to decrease disease activity and subsequent flares in both nonpregnant ${ }^{6}$ and pregnant patients ${ }^{7}$. Other potential benefits include a decreased risk of infection ${ }^{8}$ and thrombosis ${ }^{9}$. HCQ has been shown to exert a positive effect on overall survival ${ }^{10}$. In a large cohort of multiethnic patients with SLE (the LUMINA cohort), HCQ prevented renal and central nervous system disease ${ }^{11,12}$. Finally, a recent report suggests that maternal use of HCQ may decrease the risk of cardiac manifestations of neonatal lupus ${ }^{13}$.

Despite these benefits and its current use in over 70 countries, chloroquine and HCQ remain unavailable for clinical use for rheumatology patients in Japan. This unavailability stems from a series of lawsuits in the 1970s as a result of chloroquine retinal toxicity, which was first reported by Cambiaggi in $1957^{14}$ and further confirmed by Hobbs, et al in $1959^{15}$. Interestingly, chloroquine was widely used in Japan for a variety of clinical indications from 1955 through the early 1970s, including malaria, RA, and SLE, as well as in diseases such as epilepsy and chronic nephritis, in which baseline risk of retinal toxicity was likely higher to begin with ${ }^{16}$. The dangers associated with chloroquine use were compounded by the absence of rigorous safety screening protocols, despite the known potential for retinal toxicity. As a result, chloroquine was withdrawn from the Japanese market in 1974.

In the last decade, the clear benefits of antimalarial agents in rheumatological diseases have been increasingly recognized, by the growing cohort of returnee patients already treated with HCQ overseas as well as US-trained rheumatologists returning to Japan for clinical practice. In 2009, an initiative began to promote the study and introduction of HCQ into clinical care in Japan, appreciating the importance of updated safety screening protocols ${ }^{17,18}$, including earlier detection of retinal toxicity with newer ophthalmologic modalities such as multifocal electroretinogram, spectral domain optical coherence tomography, or fundus autofluorescence. Given its wide use as a standard of care worldwide, there is little reason to support HCQ's continued absence from the market. Unsurprisingly, a recent small study of HCQ in Japanese patients with SLE showed benefit in cutaneous disease, arthritis, and fatigue ${ }^{19}$. To this end, 2012 will see the first clinical trial of HCQ for SLE in Japan.

We hope that an understanding of the history of antimalarial agents in Japan - a legacy that precluded the appropriate use of an efficacious therapy - will soon lead to an era of improvement of patient care, survival, and quality of life for patients with SLE in Japan.

MITSUMASA KISHIMOTO, MD, PhD, Division of Allergy and Rheumatology, St. Luke's International Hospital, Tokyo; GAUTAM A. DESHPANDE, MD, Center for Clinical Epidemiology, St. Luke's International Hospital, Tokyo; NAOTO YOKOGAWA, MD, Department of Rheumatology, Tokyo Metropolitan Tama Hospital, Tokyo; JILL P. BUYON, MD, Department of Rheumatology, New York University Hospital for Joint Diseases, New York, New York, USA; MASATO OKADA, MD, Division of Allergy and Rheumatology, St. Luke's International Hospital, 9-1 Akashi-cho, Chuo-ku, Tokyo 104-8560, Japan. Address correspondence to Dr. M. Kishimoto; E-mail: mkishimo@luke.or.jp

\section{REFERENCES}

1. Wallace D. The history of antimalarials. Lupus 1996;5 Suppl 1:S2-3.

2. O'Dell JR, Haire CE, Erikson N, Drymalski W, Palmer W, Eckhoff $\mathrm{PJ}$, et al. Treatment of rheumatoid arthritis with methotrexate alone, sulfasalazine and hydroxychloroquine or a combination of all three medications. N Engl J Med 1996;334:1287-91.

3. Dixon JS, Pickup ME, Bird HA, Lee MR, Wright V, Downie WW. Biochemical indices of response to hydroxychloroquine and sodium aurothiomalate in rheumatoid arthritis. Ann Rheum Dis 1981;40:480-8.

4. Kim WU, Seo YI, Park SH, Lee WK, Lee SK, Paek SI, et al. Treatment with cyclosporine switching to hydroxychloroquine in patients with rheumatoid arthritis. Ann Rheum Dis 2001;60:514-7.

5. Tishler M, Yaron I, Shirazi I, Yaron M. Hydroxychloroquine treatment for primary Sjogren syndrome: Its effect on salivary and serum inflammatory markers. Ann Rheum Dis 1999;58:253-6.

6. Ruiz-Irastorza G, Ramos-Casals M, Brito-Zeron P, Khamashta MA. Clinical efficacy and side effects of antimalarials in systemic lupus etythematosus: A systematic review. Ann Rheum Dis 2010;69:20-8.

7. Clowse MEB, Magder L, Witter F, Petri M. Hydroxychloroquine in lupus pregnancy. Arthritis Rheum 2006;54:3640-7.

8. Ruiz-Irastorza G, Olivares N, Ruiz-Arruza I, Martinez-Berriotxoa A, Egurbide MV, Aguirre C. Predictors of major infections in systemic lupus erythematosus. Arthritis Res Ther 2009;11:R109.

9. Jung H, Robba R, Su J, Shariati-Sarabi Z, Gladman DD, Urowitz $\mathrm{M}$, et al. The protective effect of antimalarial drugs on thrombovascular events in systemic lupus erythematosus. Arthritis Rheum 2010;62:863-8.

10. Shinjo SK, Bonfa E, Wojdyla D, Borba EF, Ramirez LA, Scherbarth HR, et al. Antimalarial treatment may have a time-dependent effect on lupus survival: Data from a multinational Latin America inception cohort. Arthritis Rheum 2010;62:855-62.

11. Fessler BJ, Alarcon GS, McGwin G Jr, Roseman J, Bastian HM, Friedman AW, et al. Systemic lupus erythematosus in three ethnic groups: XVI. Association of hydroxychloroquine use with reduced risk of damage accrual. Arthritis Rheum 2005;52:1473-80.

12. Pons-Estel GJ, Alarcon GS, McGwin G Jr, Danila MI, Zhang J, Bastian HM, et al. Protective effect of hydroxychloroquine on renal damage in patients with lupus nephritis: LXV. Data from a multiethnic US cohort. Arthritis Rheum 2009;61:830-9.

13. Izmirly PM, Kim MY, Llanos C, Le PU, Guerra MM, Askanase $\mathrm{AD}$, et al. Evaluation of the risk of anti-SSA/Ro-SSB/La antibody-associated cardiac manifestations of neonatal lupus in fetuses of mothers with systemic lupus erythematosus exposed to hydroxychloroquine. Ann Rheum Dis 2010;69:1827-30.

14. Cambiaggi A. Unusual ocular lesions in a case of systemic lupus erythematosus. Arch Ophthalmol 1957;57:451-7.

15. Hobbs HE, Sorsby A, Freedman A. Retinopathy following chloroquine therapy. Lancet 1959;2:478-80.

16. Marmor MF, Carr RE, Easterbrook M, Farjo AA, Mieler WF; American Academy of Ophthalmology, et al. Recommendations on screening for chloroquine and hydroxychloroquine retinopathy: A report by the American Academy of Ophthalmology. Ophthalmology 2002;109:1377-82.

17. College of Ophthalmologists. Chloroquine, hydroxychloroquine and the eye. London: College of Ophthalmologists; 1993.

18. Marmor MF, Kellner U, Lai TY, Lyons JS, Mieler WF; American Academy of Ophthalmology. Revised recommendations on screening for chloroquine and hydroxychloroquine retinopathy. Ophthalmology 2011;118:415-22.

19. Yokogawa N, Kato Y, Sugii S, Inada S. Response to hydroxychloroquine in Japanese patients with systemic lupus erythematosus using the Cutaneous Lupus Erythematosus Disease Area and Severity Index (CLASI). Mod Rheumatol 2011 Aug 14 [E-pub ahead of print].

J Rheumatol 2012;39:6; doi:10.3899/jrheum.111569 